\title{
Design of the Control System of the Wind Board Based on MCU
}

\author{
Feng Haiqin ${ }^{1}$ Liao Bin $^{2}$ \\ ${ }^{1}$ Automotive and Information Engineering Department, Urban Vocational College of Sichuan, \\ Chengdu Sichuan 610101,China; \\ 2.School of Business ,Sichuan Normal University, Chengdu Sichuan 610101,China)
}

\begin{abstract}
The wind board control system is designed, taking MSP430F149 as the core control chip and STC89C52 as the auxiliary control chip. This system adopts 12864LCD as the display, selects the working mode and sets the wind board position angle by the button. And the system detect the change of wind board's angle in real time through the acceleration sensor ADXL345 which have high accuracy, change the duty cycle of PWM using the increment PID algorithm. Thus the speed of 2 DC fan can be adjusted in order to set up the wind board to a preset angle. The wind board can smoothly and accurately reach the preset angle under the no-load condition, and can realize the fast periodic swing between the two angles. What's more, the dynamic position and angle of the wind board can be displayed on the LCD screen in real time. The system operation interface is friendly.
\end{abstract}

Keywords: MSP430F149 MCU; Wind Board System; Acceleration sensor; Increment PID

\section{Introduction}

With the development of electronic information technology, the application area of air conditioning and ventilation systems are becoming wider. In order to improve the utilization of energy, enhance the control ability and stability of system, the measurement and control of angle are very important. For that reason, we design the wind board control system which taking MSP430F149 as the core control chip and STC89C52 as the auxiliary control chip. The system is designed considering the control of wind board's angle, dwell time and swing period, and so on. The button is used to select the working mode and set the position and angle of the wind board. The speed of the DC motor is controlled to rotate the wind board to preset angle, and return smoothly to the fixed position in the end.

\section{Overall System Design}

The system is mainly made up of MCU module, power supply module, DC motor drive module, angle measurement module, button module, display module and sound and light prompt module. After initialization, the preset angle of the wind board is set by pressing the button. Two DC motors are used to drive the two sides of the wind board. The acceleration sensor ADXL345 detects the angle and position of the wind board, then sends the detected information to the main control chip MSP430F149 to handle. And the PWM signal generated by single-chip STC89C52 which to control DC motor, is integrated into the motor drive chip L298N, adjust the speed of DC motor, change the size of the wind, adjust the rotation angle of wind board in real-time, and maintain its balance and stability. When the wind board reach the preset position, the buzzer prompt sounds, LED flash, by the time, the angle and position of the wind board is displayed on the LCD screen. The scheme diagram of overall system design as figure 1 shows

MOE (Ministry of Education in China) Youth Project of Humanities and Social Sciences (Grant No. 14YJCZH089) 


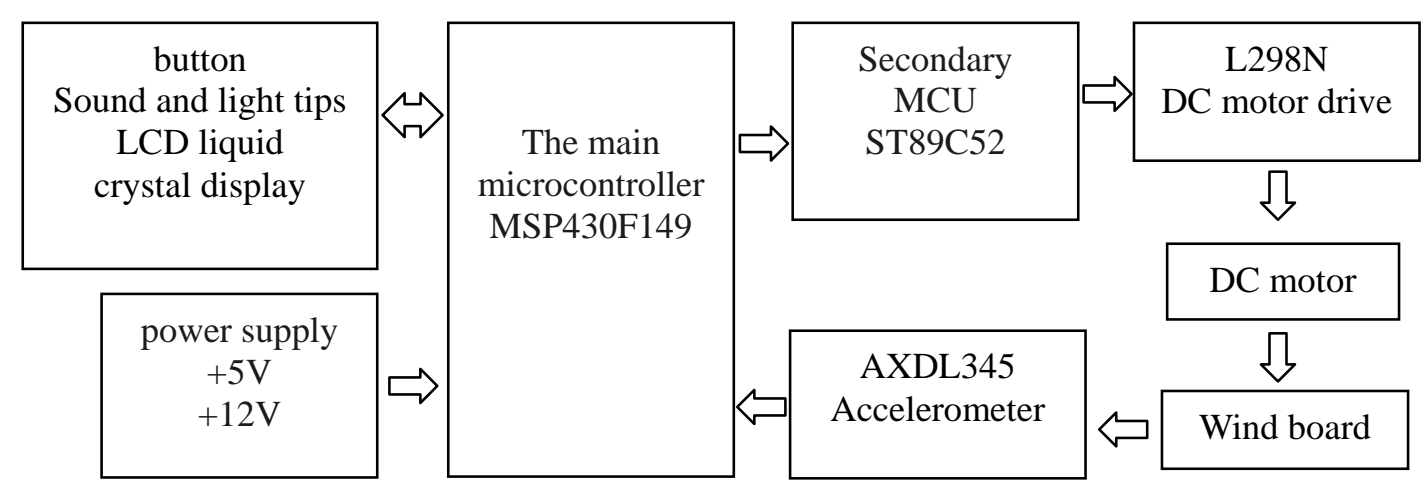

Fig.1 The overall system design

\section{Hardware Circuit}

Single-Chip Module.The system is controlled by MSP430F149 and dual-chip ST89C52, and take the 16-bit microcontroller MSP430F149 produced by TI as the main control chip to receive information input by button. It obtain the angle and position of wind board through the acceleration sensor AXDL345, then the buzzer prompt sounds after wind board reached the preset position successfully, and the 12864LCD display the angle and position of the wind board. According to the microcontroller MSP430F149, the microcontroller ST89C52 obtain the angle and position of the wind board, then generate the PWM signal to control the DC motor, and adjust the strength of wind output to blow the wind board near the set angle. After that, enable the PID algorithm, according to the feedback of the real-time angle, adjust the wind board to approach the preset angle gradually through PWM, then the speed of fan can be controlled. The two kinds of single-chip are combined to control the system, it meet the functional requirements and have a high cost-effective.

Power Supply.As the system needs 5V DC voltage to supply power, while the fan needs $12 \mathrm{~V}$ DC voltage, so the system provides this two sets of power supply. The power supply is composed of transformer part, filtering part and voltage stabilizing part. Firstly, the 220V AC voltage is step-down by transformer. Secondly, after disposed by the bridge rectifier and filter, it is separated from three-terminal voltage regulator using the characteristic of Darlington high-current. Low-current three-terminal voltage regulator, high-current flow through the Darlington tube. Thus, the system not only ensure a high current with small ripple, but also make a safe work.

DC Motor Drive Module.DC fan's drive is controlled by the integrated chip L298N, this chip is a dedicated motor driver chip that can be used to drive DC motor and stepper motor. This chip has the high-voltage of $\mathrm{H}$ bridge and the high-current full-bridge driver, it is controlled by the standard logic-level control and has two enable control terminals that can simultaneously control the 2-way motor. L298N is constant voltage constant current chip which can effectively prevent the motor burned. Its maximum operating current is $2.5 \mathrm{~A}$, rated power is $25 \mathrm{~W}$.

Acceleration Sensors.The ADXL345 is a digital three-axis accelerometer with ultra-low power consumption, its resolution is high, and the measurement is in the range of $\pm 16 \mathrm{~g}$. The sensor is small, it's easy to install, and it can measure the variation of tilt angle less than $1.0^{\circ}$ and the acceleration in three direction of X, Y, Z. The ADXL345 is ideal for mobile applications where it can measure static gravitational acceleration in tilt detection applications, as well as dynamic acceleration due to motion or shock. Using the high-precision three-axis acceleration sensor AXDL345 which will always have an acceleration due to the presence of gravity - an dip angle will be determined according to the acceleration and the angle of the other axis. The angle $\theta$ of wind board measured by AXDL345 is read in real time by MCU MSP430F149. By comparing with the set value, the PWM's output signal is changed, the speed of DC motor is adjusted, and the wind power is changed, so that to meet the requirements of adjusting the wind board's angle.

Ancillary Parts.The auxiliary of the system consist of three parts, they are button input, sound and light tips and 12864 LCD display. The button input part provides the position and angle of the wind board that preset by system. After the preset purpose is reached, the buzzer will send out the prompt sound and the LED will blink to indicate that the system has successfully completed the 
task. The button has two independent part, one provide working mode selection, another set the position and angle that the fan need to arrive. In order to simplify the circuit design, the sound and light tips part selects the buzzer and light-emitting diodes. And display part selects the 12864LCD whose display content is rich, clear, fast, it can display Chinese characters, it's information is large and man-machine interface is friendly. What's more, the auxiliary use 5V DC to supply power, and its external circuit configuration is simple and cost-effective. It is convenient to view the work state of the DC motor according to the real-time position and angle of wind board displayed by 12864LCD.

\section{Software Design}

After the system is switched on, initialize operation is carried out to initialize the 12864LCD and the acceleration sensor AXDL345, and 5ms timer interrupt is turn on. According to the display interface, the user can select the working mode and input the parameters by pressing the button. The fuzzy rough algorithm and the PID detailed algorithm are combined, and the digital closed-loop feedback is formed using the acceleration sensors, thus get a result that is the increments of two-way PWM. Then control the PWM duty cycle of two motors using STC89C52, the calculation results is passed to every control unit through the IO port parameters, so that the wind board can response quickly and stable in preset angle rapidly. After the dwell time is stable, the wind board returns to the initial position. The procedures is written using $\mathrm{C}$ language in the Keil51 development environment.

\section{Test Results and Analysis}

Test Methods.Using the stopwatch to test, when the operator set the position and angle through the button, start timing. When reach the preset position and angle, the buzzer send out the prompt sounds, and LED blink. Thus obtain the time and continue Timing until the wind board back to the end.

Test Data.The test is divided into two cases. Firstly, the wind board start movement from rest until reach the transition time of specified control angle and the dwell time of setted angle. When the wind board stabilizes at the specified control angle, read out the actual value with the protractor. The test data are shown in Table 1. Secondly, when the wind board is placed in the end position, turn on the power. Then enter two preset angle values in turn through the keyboard, and start the stopwatch to time. When the wind board start movement from rest, record down three data, they are the time for the wind board first reach the preset angle $\theta 1$, the time for the wind board first reach the preset angle $\theta 2$, and the swinging period for the wind board swings 3 times between the two preset angles. Then use the protractor to read the actual value for the wind board reach the preset angles twice. Finally, observe whether the wind board stay in the starting position smoothly after completing the action. This test data are shown in Table 2. According to the test data, the size of the wind affects the wind-board jitter, but the wind-board jitter is small and the transition time is shorter within $90^{\circ}$. After lager than $90^{\circ}$, the time for the wind board to reach the set angle is longer and the transition time is longer, But the residence time is shorter than that within $90^{\circ}$. All the test angles are accurate, and can achieve the desired requirements.

Table 1 Test data

\begin{tabular}{cccccc}
\hline $\begin{array}{c}\text { Number of } \\
\text { Measurements }\end{array}$ & $\begin{array}{c}\text { Transitio } \\
\mathrm{n} \\
\text { Time }\end{array}$ & $\begin{array}{c}\text { Dwell } \\
\text { Time }\end{array}$ & $\begin{array}{c}\text { Set Angle } \\
\theta\end{array}$ & $\begin{array}{c}\text { Test An- } \\
\text { gle } \\
\theta\end{array}$ & Error \\
\hline 1 & $10 \mathrm{~s}$ & $6 \mathrm{~s}$ & $61^{\circ}$ & $64^{\circ}$ & $3^{\circ}$ \\
2 & $9 \mathrm{~s}$ & $6 \mathrm{~s}$ & $81^{\circ}$ & $81^{\circ}$ & $0^{\circ}$ \\
3 & $7 \mathrm{~s}$ & $5 \mathrm{~s}$ & $91^{\circ}$ & $90^{\circ}$ & $1^{\circ}$ \\
4 & $12 \mathrm{~s}$ & $6.5 \mathrm{~s}$ & $121^{\circ}$ & $118^{\circ}$ & $3^{\circ}$ \\
5 & $13 \mathrm{~s}$ & $7 \mathrm{~s}$ & $130^{\circ}$ & $128^{\circ}$ & $2^{\circ}$ \\
\hline
\end{tabular}


Table 2 Test data

\begin{tabular}{cccccc}
\hline $\begin{array}{c}\text { Number of } \\
\text { Measurements }\end{array}$ & $\begin{array}{c}\text { Transitio } \\
\mathrm{n} \\
\text { Time }\end{array}$ & $\begin{array}{c}\text { Dwell } \\
\text { Time }\end{array}$ & $\begin{array}{c}\text { Set Angle } \\
\theta\end{array}$ & $\begin{array}{c}\text { Test Angle } \\
\theta\end{array}$ & Error \\
\hline 1 & $4 \mathrm{~s}$ & $6 \mathrm{~s}$ & $61^{\circ}-120^{\circ}$ & $61^{\circ}-122^{\circ}$ & $3^{\circ}$ \\
2 & $6.7 \mathrm{~s}$ & $6.5 \mathrm{~s}$ & $80^{\circ}-100^{\circ}$ & $83^{\circ}-97^{\circ}$ & $5^{\circ}$ \\
3 & $9 \mathrm{~s}$ & $4 \mathrm{~s}$ & $70^{\circ}-110^{\circ}$ & $69^{\circ}-111^{\circ}$ & $2^{\circ}$ \\
4 & $8.5 \mathrm{~s}$ & $5 \mathrm{~s}$ & $60^{\circ}-90^{\circ}$ & $60^{\circ}-90^{\circ}$ & $0^{\circ}$ \\
5 & $7 \mathrm{~s}$ & $6 \mathrm{~s}$ & $75^{\circ}-115^{\circ}$ & $75^{\circ}-117^{\circ}$ & $2^{\circ}$ \\
\hline
\end{tabular}

\section{Conclusion}

the wind board control system is designed using microcontroller MSP430F149 as the main control chip, microcontroller STC89C52 as the auxiliary control, the rotation angle of the wind board range in $45^{\circ} 135^{\circ}$. The system uses the acceleration sensor ADXL345 which has high-precision to acquire the angle signal, and adjusts the PWM duty cycle of the motor by the incremental PID algorithm. The integrated motor drive chip L298N drives the two DC fans and realizes the speed regulation, so that the wind board not only can reach and stable at any preset angle, but also can swing periodically between any two angles. What's more, the angle and position of the wind board can be displayed on the LCD screen in real-time. In a word, this system response rapidly, and has high control precision and the function of self sound and light tips. The wind board control system can be widely used in many technical filed, such as the air conditioning and ventilation systems, and the measurement and control of angle, and so on.

\section{References}

[1]WANG Hai-yang.The design of the control device for the wind board basedon STC12C5A60S2 [J].Technique \& Education.2016,30(2):57-61.

[2]LI De-yao.The Design of Panel Control System Based on C8051F020 Single Chip Microcomputer[J].Computing Technology and Automation. 2012,31(2):66 -70.

[3]ZHI Hai-su.Design and test for windsurfi ng control system based single chip computer[J].Manufacturing Automation.2012,34(6):133-135.

[4]LUO Le.A design of panels control system based on STC12C60S2 MCU[J].Journal of Chongqing University of Arts and Sciences ( Natural Science Edition).2013,31(8):30-32.

[5] ZHONG Ling-ling. The Design of Panels Control System Based on Single-chip Microcomputer[J].Computer Knowledge and Technology.2011,35(7):9246-9250.

[6] FENG Bang-jun.Design of the Control System of the Wind Board Based on MSP430 MCU[J].Electrical Engineering Technology.2016, 45 (6): 85-87. 